\title{
Microstructural Evolution Under Low Shear Rates During Rheo Processing of LM25 Alloy
}

\author{
Sunitha Jallepalli Satya, Vivek Kumar, Nilam S. Barekar, Koushik Biswas, and Brij K. Dhindaw
}

(Submitted August 26, 2011; in revised form January 13, 2012)

\begin{abstract}
Microstructural features of LM25 alloy processed by two different routes: (1) conventional casting, and (2) shear casting based on inclined heated surface are studied. The microstructures of the primary phase for the shear-cast samples show rosette or ellipsoidal morphologies. Heat transfer of contacting melt with the inclined tube surface and shear stress exerted on the layers of the melt as result of gravitational force are crucial parameters for the microstructural evolution. Compared to those produced by conventional casting, shear-cast samples have a much improved tensile strength and ductility due to globular microstructure.
\end{abstract}

Keywords convection, microstructure, semi solid, shear stress

\section{Introduction}

Since the advent of metal casting, solidification of alloys has been treated as a natural process. Nearly 39 years have since elapsed after the initial experiments of Spencer (Ref 1) on Sb$15 \% \mathrm{~Pb}$ alloy with semisolid metal processing which has clearly demonstrated that the solidification process can be manipulated positively and effectively by external means to achieve the preferred microstructure (Ref 2, 3). Many studies have been conducted to understand the fundamentals of microstructural evolution and engineering aspect of semisolid processing. A range of reviews are available in the literature (Ref 2-6). Several variants of applying shear force to break the dendrites during solidification have been suggested (Ref 3). Continuous shear during solidification leads to rosette or spherical morphology (Ref 2), which is beneficial for the enhancement of mechanical properties. Today semisolid processing has established itself as a scientifically sound technology for the production of metallic components of high integrity and graceful performance in service.

Nonetheless, even now interest is still being shown in developing the semisolid process, with the intent of making it technologically simple and viable. One route suggested is the processing of the alloy by using inclined, controlled heated plates (Ref 7-12). This process involves low shear rates while melt is flowing on the inclined surface. The process is attractive due to the versatility expected, ease of processing, and economic

Sunitha Jallepalli Satya, Vivek Kumar, and Koushik Biswas, Metallurgical and Materials Engineering, Indian Institute of Technology, Kharagpur, Kharagpur, West Bengal, India; Nilam S. Barekar, Institute for Complex Materials, Leibniz Institute for Solid State and Materials Research Dresden, Helmholtzstraße 20, 01069 Dresden, Saxony, Germany; and Brij K. Dhindaw, School of Materials and Mineral Resources Engineering, University Sains Malaysia, 14300, Nibong Tebal, Penang, Malaysia. Contact e-mail: n_barekar@yahoo. co.in. aspects that have been the limiting factors to a great extent in the development of semisolid processing. Studies have been performed to examine the effect of length and angle of slope on the evolution of the morphology of the grains (Ref 7, 13, 14). Legoretta et al. (Ref 15) have investigated the effect of the flow behavior on the solidification process using analogue system. Studies carried out so far has been helpful to some extent in understanding the complicated microstructural evolution during inclined low-shear processing of the alloys. However, the explanation for the various stages of the development of the microstructure during flow still remains ambiguous.

Post-forming heat treatment is one of the key parameters for improving the mechanical properties of cast parts. The heat treatment cycles that are currently applied to semisolid-processed components are mostly those which are used for the conventionally cast components having dendritic structure. These heat treatments are not necessarily optimal treatments, as the differences exist in the solidification history and the microstructure of rheo and conventionally cast samples (Ref 16).

Hence, the present study was undertaken with the aim to examine the effect of low-melt shearing on LM25 alloy having wide semisolid range. The prime objective of the study is to analyze possible relationship of the shear force, the heat transfer, and the flow behavior during inclined low-shear processing with modification of primary phase and to investigate the role of microstructural changes of the as-processed samples on the mechanical properties of the alloy. The efforts have been undertaken to optimize the T6 heat-treatment parameters for low-sheared, rheo-processed LM25 alloy. The study will provide some insight into the microstructural development during inclined low-shear processing.

\section{Experimental}

\subsection{Alloy Used}

The composition of the aluminum-based LM25 alloy used in the present investigation is presented in Table 1 . The given alloy was chosen for the study because it has a larger freezing range (liquidus and solidus are at $615 \pm 2$ and $577 \pm 2{ }^{\circ} \mathrm{C}$, respectively) which enables a better control of the shear and 
Table 1 Chemical composition (wt.\%) of the LM25 alloy used in this study

\begin{tabular}{lccccccr}
\hline Si & Mg & Fe & Cu & Mn & Ti & Zn & Al \\
\hline 7.01 & 0.40 & 0.20 & 0.08 & 0.04 & 0.12 & 0.1 & Rem. \\
\hline
\end{tabular}

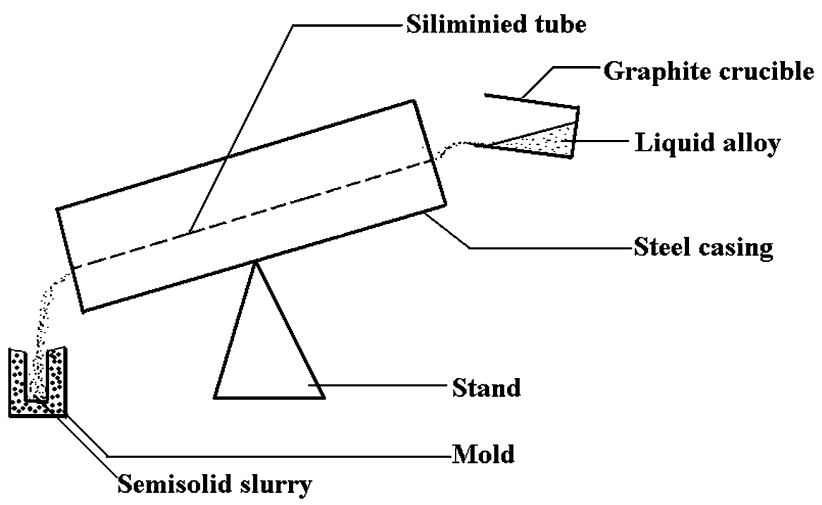

Fig. 1 Schematic illustration of inclined set-up

fraction of solid in the semisolid range and the microstructural development could be studied precisely. For some experiments, sodium was added to modify the coarse platelet morphology of the eutectic silicon.

\subsection{Inclined Set Up}

Figure 1 shows the set-up used to study the effect of processing on the microstructure of the LM25 alloy flowing on an inclined siliminide tube. The length of the slope was $2 \mathrm{~m}$, and inclination was varied from $10^{\circ}$ to $30^{\circ}$. The siliminide tube was enclosed in a steel casing with a refractory coating. The siliminide tube was painted with Zirconia over its inner diameter to avoid sticking of the metal to the tube. The temperature at the pouring end of the slope was maintained below liquidus and the exit end near to the solidus of the alloys to be cast.

\subsection{Rheocasting}

A charge of $\sim 1.5 \mathrm{~kg}$ of aluminum alloy was melted at $700{ }^{\circ} \mathrm{C}$ with an induction furnace. The hexachloroethane was added to reduce the hydrogen content before pouring down the slope. Approximately at $10{ }^{\circ} \mathrm{C}$ superheat, the alloy was poured on the siliminide tube. The semisolid slurry obtained at the lower end was cast in sand and graphite molds $\left(12^{\varphi} \times 150^{1} \mathrm{~mm}^{2}\right)$. Samples produced by this method are referred as "shear-cast" samples. The sand and graphite molds were preheated to get rid of moisture. For comparison with the shear cast results, some samples were cast directly into the mold without the slope (i.e., conventionally cast). Few experiments were conducted for Na-modified LM25 alloy by the inclined set up and compared with the conventionally cast alloy.

\subsection{Heat Treatment}

The shear-cast specimens were heat treated using T6 heat treatment. Solution heat treatment was performed at $540{ }^{\circ} \mathrm{C}$ for 4,6 , and $8 \mathrm{~h}$; followed by a water quench $\left(25^{\circ} \mathrm{C}\right)$. The samples were then artificially aged at $150,175,200$, and $225^{\circ} \mathrm{C}$ for 2 , $4,8,12$, and $16 \mathrm{~h}$.

\subsection{Metallography and Mechanical Testing}

The small ingot samples from the shear cast and the conventionally cast experiments were sectioned for metallographic analysis. The specimens for microscopical observation were prepared by the standard technique of grinding with $\mathrm{SiC}$ abrasive papers, polishing with diamond paste, and etched in Keller's reagent to reveal the morphology. The microstructures were examined using an optical microscope (Leica, DMLM, Germany). The shape factor or sphericity $(S)$ of primary $\alpha-\mathrm{Al}$ particles was calculated using the equation:

$S=\frac{4 \pi A}{P^{2}}$

where $A$ and $P$ are the total area and the peripheral length of the primary particles on the plane of polish surface, respectively. Therefore, $S$ is 1 for perfectly spherical particles. For tensile testing, the specimens were prepared as per ASTM standard $(\mathrm{E} 8 \mathrm{M})$. The tensile tests were performed using Tinius Olsen H50K-S testing machine (USA) with a strain rate of $10^{-3} \mathrm{~s}^{-1}$. The fractured surfaces of the tensile specimens were observed under scanning electron microscope (JEOL JSM-5800). Hardness of the shear-cast and the heat-treated samples were measured with Vickers hardness tester (UHL VMHT MOT, Germany) using a load of 49 N. At least four specimens were tested to ensure reproducibility of the results.

\section{Results and Discussion}

\subsection{Microstructural Assessment of Primary Phase}

Representative optical micrographs of LM25 and Na-modified LM25 obtained from the conventionally cast and the shear-cast samples are presented in Fig. 2 and 3, respectively. Microstructures of the shear-cast sample show significant difference in comparison to the conventionally cast samples with respect to the morphology of primary phase. In the shear-cast sample, the primary solid phase is present as rosette or ellipsoid (Fig. 2c-h, 3b, c), whereas for the conventionally cast sample it is in the classical form of dendrites (Fig. 2a, b). The microstructural features of the shear and conventionally cast samples are summarized in Table 2 . Higher value of the shape factor for the shear-cast sample indicates a significant improvement in the morphology of primary $\alpha$-Al particles. A higher thermal conductivity of the graphite compared to the sand mold resulted in smaller size particles. The shape factor shows higher values for the alloy cast at higher inclination angle. The fraction of solid of $\alpha$-Al phase decreases with increasing angle of inclination.

\subsection{The Basic Effect of the Slope}

Solidification sequence involved in the inclined low-shear processing is a complex combination of heat-fluid flow-mass transfer in the liquid and/or solid state. Heat transfer of contacting melt with the inclined tube surface and shear stress exerted on the layers of the melt as result of gravity force are crucial parameters to change the microstructure. When the molten alloy first touches the slope, it forms an "elliptical impact zone" where material is spread. The impact zone on the slope is thought to be the principal source of nuclei (Ref 12). In the first instance, solidification can start on the surface of siliminide tube when the melt temperature falls below the 

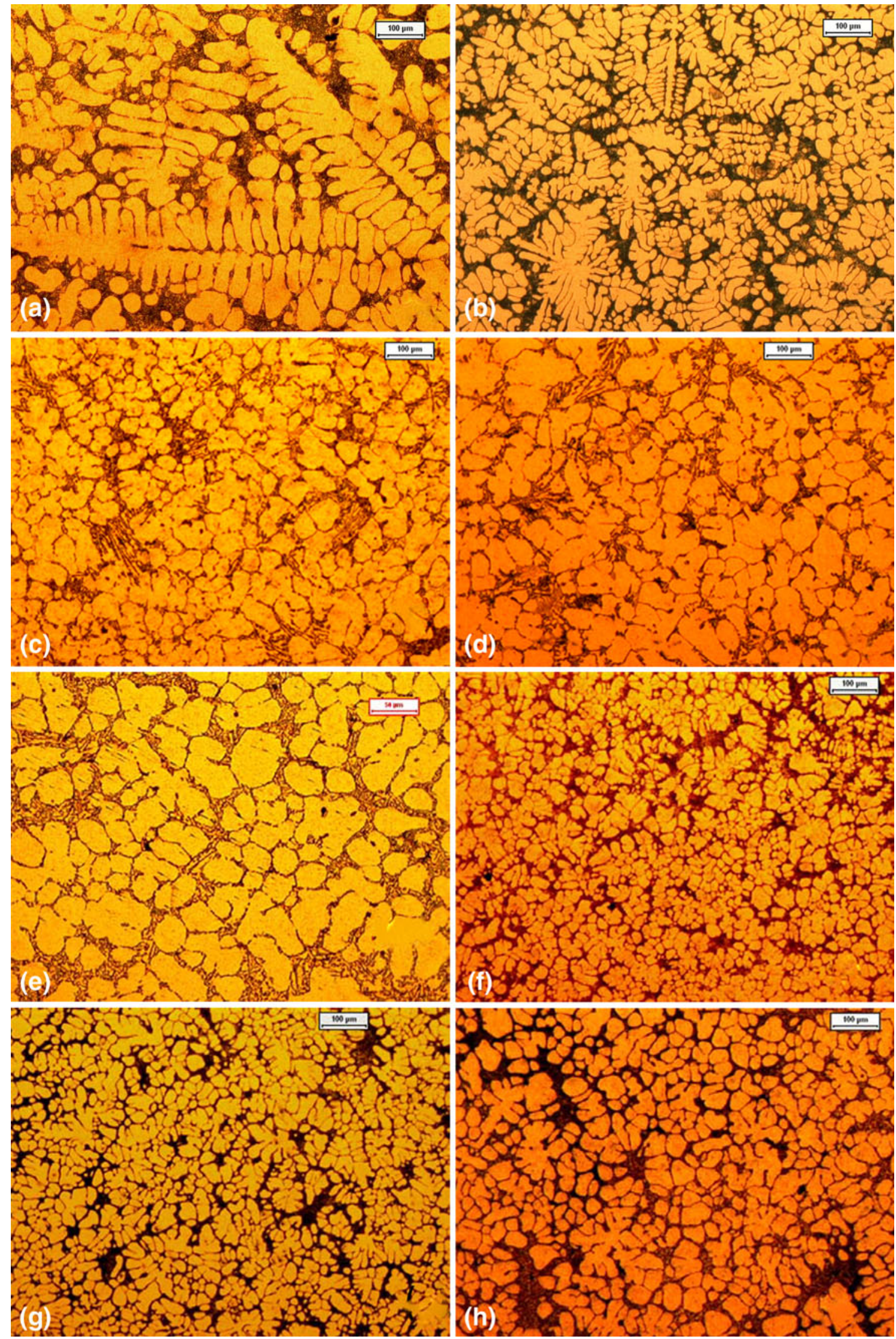

Fig. 2 LM25 alloy conventionally cast in the (a) sand mold (b) graphite mold showing dendritic morphology of primary $\alpha$-Al (bright phase). Shear-cast LM25 alloy in the sand mold with (c) $10^{\circ}$, (d) $20^{\circ}$, and (e) $30^{\circ}$ inclinations showing rosette morphology. Shear-cast LM25 alloy in the graphite mold with (f) $10^{\circ}$, (g) $20^{\circ}$, and (h) $30^{\circ}$ inclinations showing rosette morphology 

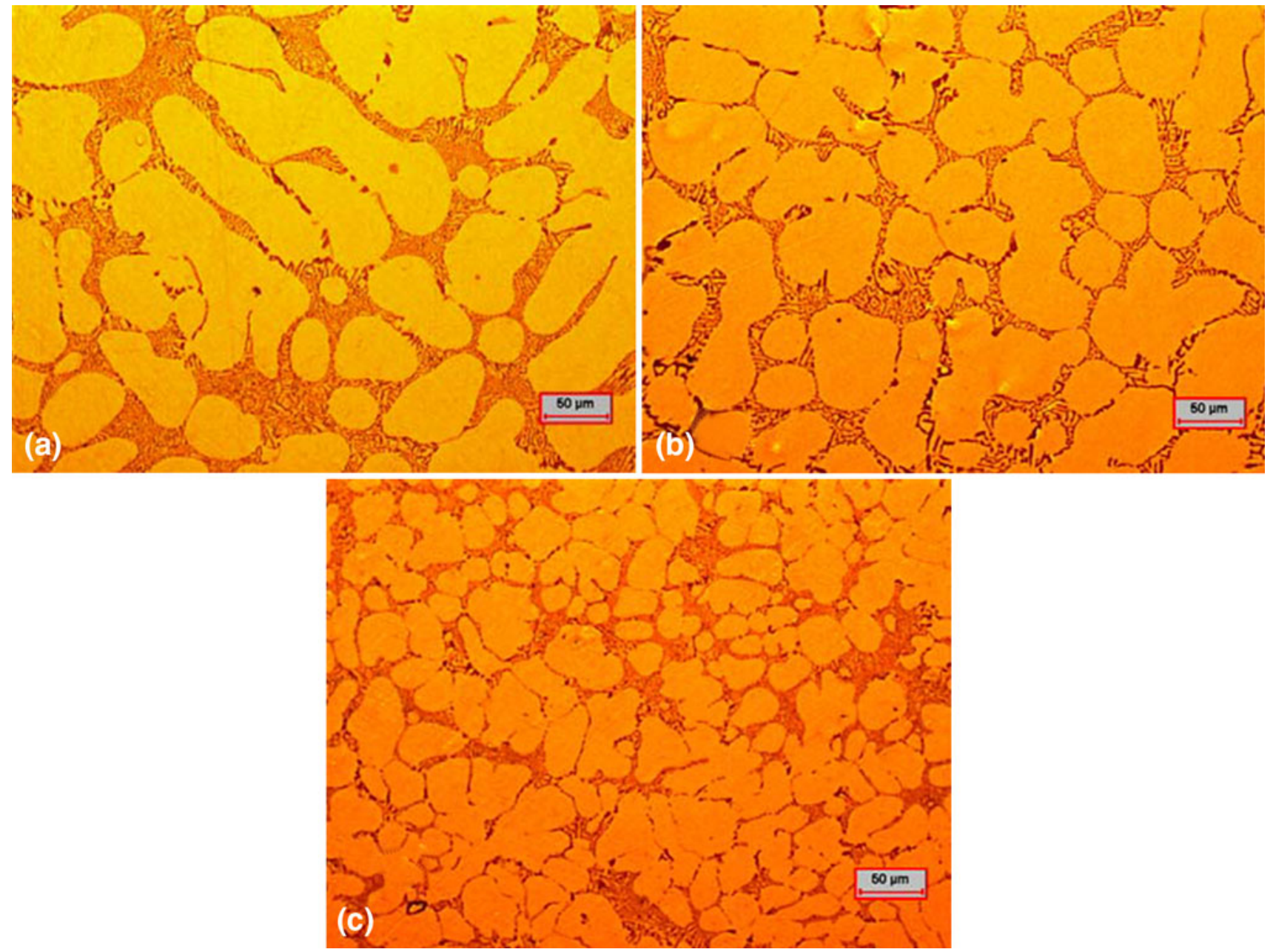

Fig. 3 Na-modified LM25 alloy: (a) conventionally cast in the sand mold, (b) shear cast with $20^{\circ}$ inclination in the sand mold, and (c) shear cast with $20^{\circ}$ inclination in the graphite mold

Table 2 Analysis of microstructural features of the primary $\alpha$-Al phase

\begin{tabular}{llcc}
\hline Alloy and mold & \multicolumn{1}{c}{ Method } & $\begin{array}{c}\text { Shape } \\
\text { factor }\end{array}$ & $\begin{array}{c}\text { Fraction } \\
\text { of solid }\end{array}$ \\
\hline LM25 and & Conventionally cast & 0.03 & $\ldots$ \\
sand mold & Shear cast $\left(10^{\circ}\right)$ & 0.39 & 0.78 \\
& Shear cast $\left(20^{\circ}\right)$ & 0.41 & 0.77 \\
& Shear cast $\left(30^{\circ}\right)$ & 0.54 & 0.75 \\
LM25 and & Conventionally cast & 0.06 & $\ldots$ \\
graphite mold & Shear cast $\left(10^{\circ}\right)$ & 0.50 & 0.78 \\
& Shear cast $\left(20^{\circ}\right)$ & 0.52 & 0.77 \\
Na-modified LM25 & Shear cast $\left(30^{\circ}\right)$ & 0.55 & 0.75 \\
and sand mold & Conventionally cast & 0.04 & $\ldots$ \\
Na-modified LM25 & Shear cast $\left(20^{\circ}\right)$ & 0.57 & $\ldots$ \\
and graphite mold & Shear cast $\left(20^{\circ}\right)$ & 0.61 & $\ldots$ \\
& & &
\end{tabular}

The error on shape factor is about \pm 0.1

liquidus. During the movement of the melt, the exerted shear stress due to gravity leads to detachment of the newly formed $\alpha$-Al phase from the surface or breaking of dendrite arms which are growing on the surface of the tube. The detachment of crystals from the surface of the inclined tube can also occur as a consequence of the solute segregation in the solidification front taking place during solid growth in a metallic alloy. The difficulty of the segregated solute atoms to disperse in the liquid is higher in the region of roots of the crystal in contact with the tube surface. This leads to smaller interface undercooling and results in lower growing rate in this region. As a consequence of this local deceleration of the growing rate a necking is developed; the necked crystal can now easily be detached from the surface where it lies (Ref 17). As the pouring continues, such initial crystals can be detached from the surface and join the melt downward. The free surface of the tube can now promote new nucleation, and successively crystals are formed and detached from this surface which can then be considered a "source" of nuclei. However, it can be argued that due to shearing process, on cooling the melt below solidification temperature, the nucleation of the primary phase may also take place throughout the melt. Some authors (Ref 7) have reported the formation of three layers during flow of the melt over the inclined surface. Bottom layer connected to the surface of the tube is a solid layer containing the primary solid phase. The middle layer is a semisolid suspension containing the melt and the growing primary solid phase. The top layer contains the molten alloy in which the rate of heat transfer is higher than that in the middle layer. The heat and solute would be transported 
because of the convection induced by the shearing. This would lead to lowering of the overall undercooling in front of the growing solid. At low undercooling, the interface of the fragmented dendrites and the freshly nucleated particles would grow as cellular morphology which is likely to be more stable because of the convection levels. These $\alpha$-Al particles are distributed in the melt during flow, and thus, we see the rosette or spherical cells in the microstructure of the shear-cast sample. Subsequently when the primary solid has grown to some extent because of the overlapping of thermal and solute fields, the undercooling temperature gets still lowered leading to the stable front growth and precluding the formation of dendrites.

\subsection{Effect of Angle of Inclination}

Based on Newton's second law for balance of forces, the shear stress $\left(\tau_{\mathrm{o}}\right)$ exerted by the surface of the tube on the flowing melt is given by Southard (Ref 18)

$\tau_{\mathrm{o}}=\gamma \sin \alpha R_{\mathrm{H}}$

where $\gamma$ is specific weight of the liquid, $\alpha$ is the angle of inclination, and $R_{H}$ is hydraulic radius formed by dividing the cross-sectional area of the flow by the wetted perimeter. By increasing the angle of inclination, the intensity of the shear stress increases as predicted by Eq 2 . As a result, more solid particles are detached from the bottom layer or are broken in the middle layer. Therefore, higher numbers of solid particles are formed into the melt which is flowing over the surface of inclined tube. When the inclination angle is higher, the fluid flow rate will tend to be high and enhances the rosette/ellipsoidal morphology. Finally these formed solid particles accompanied the remaining melt which poured into the mold, and a globular microstructure is produced. This is reflected by the higher shape factor values for the alloy cast at higher inclination angle. On the other hand, durations of the exerted shear stress and the heat transfer between the melt and the surface of inclined tube are decreased by increasing the angle of inclination. Hence the number of primary solid particles and in turn a fraction of solid phase formed in the flowing melt over the surface of inclined tube decreases. The vertical distribution of the shear stress and velocity during the melt flow are shown in Fig. 4 along with the schematic of the microstructural development.

\subsection{Mechanical Properties}

It is well known that both the structure and properties of cast specimens are sensitive to the processing technique. The tensile test values obtained for the conventionally cast and the shear-cast samples for different slope angles are given in Table 3. Compared with the conventional cast process, the shear-cast process provides samples with a slightly higher ultimate tensile strength (UTS) and higher tensile elongation. The elongation of the shearcast samples is approximately $100 \%$ higher than that of the conventionally cast samples. This is a very important feature of the shear-cast process. Table 3 shows a comparison of properties from tensile tests for Na-modified LM25 samples processed by the two techniques. The obtained values clearly demonstrate that the shear-cast process offers better tensile properties than the conventional-cast process in terms of increased strength and ductility simultaneously. The enhancement of the morphology achieved by the shear-cast process directly impacts on the properties of the cast material. The tensile fracture surfaces are

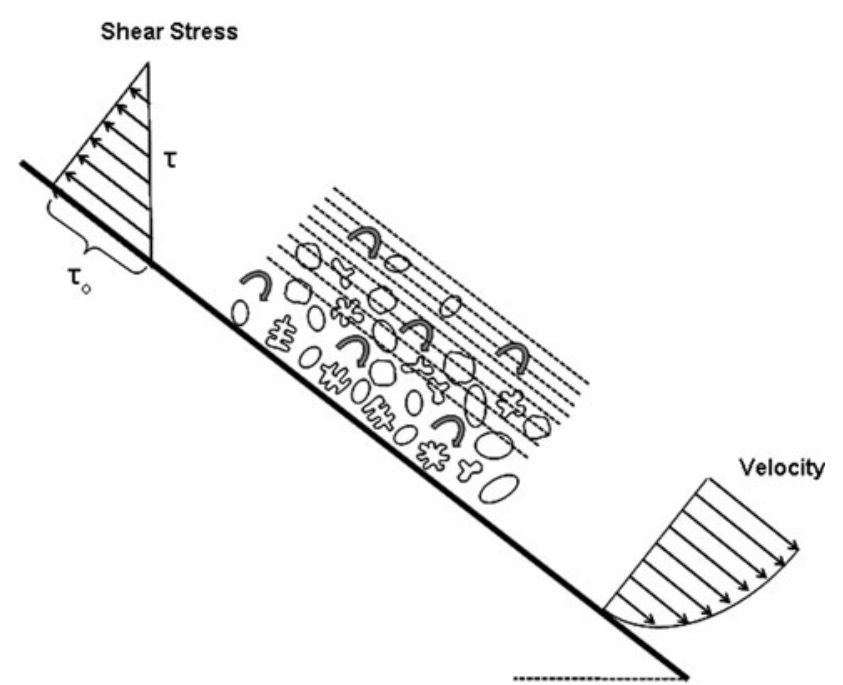

Fig. 4 The shear stress and velocity distribution and the schematic of the microstructural development during melt flow over the inclined surface

Table 3 Tensile properties of samples with and without shear for LM25 alloy

\begin{tabular}{|c|c|c|c|}
\hline Alloy and mold & Method & $\begin{array}{l}\text { UTS, } \\
\text { MPa }\end{array}$ & $\begin{array}{c}\text { Elongation, } \\
\%\end{array}$ \\
\hline \multirow{4}{*}{$\begin{array}{l}\text { LM25 and sand } \\
\text { mold }\end{array}$} & Conventionally cast & 130 & 2 \\
\hline & Shear cast $\left(10^{\circ}\right)$ & 142.6 & 4.16 \\
\hline & Shear cast $\left(20^{\circ}\right)$ & 151.2 & 4.31 \\
\hline & Shear cast $\left(30^{\circ}\right)$ & 156.1 & 4.45 \\
\hline \multirow{3}{*}{$\begin{array}{l}\text { LM25 and graphite } \\
\text { mold }\end{array}$} & Conventionally cast & 160 & 3 \\
\hline & Shear cast $\left(10^{\circ}\right)$ & 179.4 & 5.61 \\
\hline & Shear cast $\left(30^{\circ}\right)$ & 210 & 7.82 \\
\hline $\begin{array}{l}\text { Na-modified LM25 } \\
\text { and graphite mold }\end{array}$ & Shear cast $\left(20^{\circ}\right)$ & 195.5 & 12.6 \\
\hline
\end{tabular}

The standard deviation of the UTS and elongation are $6 \mathrm{MPa}$ and $0.3 \%$, respectively

helpful in elucidating the microstructural effects on the ductility and fracture properties of a material. The fractograph of the shearcast LM25 alloy is depicted in Fig. 5. Fracture surface of the alloy shows ductile fracture with various sizes of dimples, indicating superior plastic deformation that occurred before fracture.

The influences of different solution heat treatment durations and artificial ageing treatment on the LM25 alloy hardness is presented in Fig. 6. The measured hardness values of the shearcast (inclination $20^{\circ}$ ) LM25 alloy are $65 \pm 3$ and $75.5 \pm 3 \mathrm{Hv}$ for the sand and graphite molds, respectively. As expected, maximum hardness is reached in a shorter time as artificial aging temperature is increased. For the samples aged at $150{ }^{\circ} \mathrm{C}$, the hardness of the specimen increases with increasing aging time until the peak hardness is attained. Then the hardness tends to decrease upon further aging. For the samples aged at 175 and $200{ }^{\circ} \mathrm{C}$, hardness values are fairly constant after reaching the peak value, whereas hardness values decrease continuously for the samples aged at $225{ }^{\circ} \mathrm{C}$. In case of the heat-treated Al-Si-Mg alloy, the mechanism of hardening is related with the precipitation of magnesium silicide $\left(\mathrm{Mg}_{2} \mathrm{Si}\right)$ (Ref 19). $\mathrm{Si}$ and $\mathrm{Mg}$ phases form a supersaturated solid solution in $\mathrm{Al}$ phase, and 


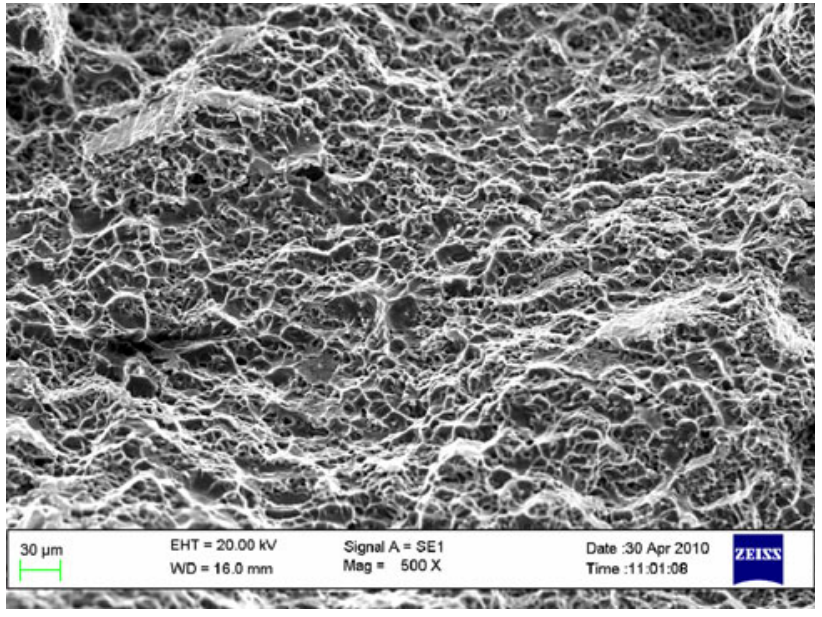

Fig. 5 Fractographs of the shear-cast LM 25 alloy $\left(30^{\circ}\right.$ inclination, graphite mold) showing ductile failure
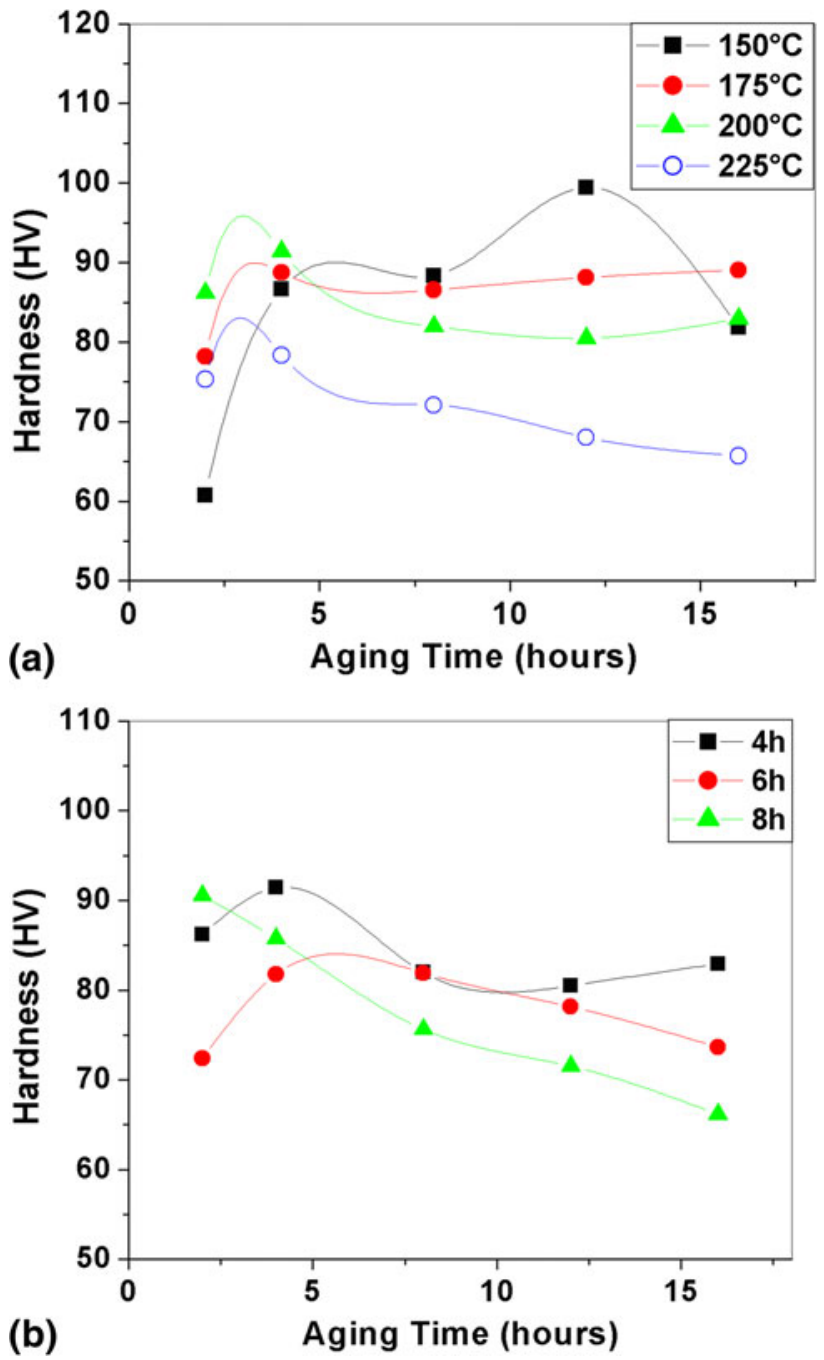

Fig. 6 Hardness of the shear-cast (inclination $20^{\circ}$, graphite mold) and the heat-treated LM25 alloy: (a) solution treated $540{ }^{\circ} \mathrm{C}$ for $4 \mathrm{~h}$ and aged at $150,175,200$, and $225^{\circ} \mathrm{C}$ for $2,4,8,12$, and $16 \mathrm{~h}$; (b) solution treated at $540{ }^{\circ} \mathrm{C}$ for 4,6 , and $8 \mathrm{~h}$ and aged at $200{ }^{\circ} \mathrm{C}$ for $2,4,8,12$, and $16 \mathrm{~h}$. The hardness values were found to be reproducible within $\pm 3 \mathrm{Hv}$ subsequently precipitate as $\mathrm{Mg}_{2} \mathrm{Si}$ phase. The high initial supersaturation leads to a rapid increase in hardness during early aging. The hardness increases with the increasing number of $\mathrm{Mg}_{2} \mathrm{Si}$ phase (Ref 20). The hardness reaches a peak value when the concentrations of $\mathrm{Al}$ matrix and precipitates are in equilibrium. The reduction of hardness is due to the growth and the coarsening of the $\mathrm{Mg}_{2} \mathrm{Si}$ phase. The longer solution treatment durations of 6-8 h were long enough to get complete dissolution of alloying elements, but relatively coarse microstructure would have probably resulted in the lower hardness values.

\section{Conclusions}

The results of the above study lead us to the following conclusions:

1. Rosette or globular structures were possible to obtain with low-shear rheocasting. This was attributed to the heat and solute transports due to the convection induced by the shearing and breaking down of the dendrite arms by shear stress.

2. The exerted shear stress increases with the increasing inclination angle of the tube. The increased shear stress enhances the morphology of $\alpha$-Al phase.

3. A good combination of the improved UTS and the tensile elongation is obtained for the shear-cast samples compared with the conventionally cast samples.

4. T6 heat treatment can strengthen the shear-cast LM25 alloy, with a peak hardness value of $100 \pm 3 \mathrm{Hv}$, when aged for $12 \mathrm{~h}$ at $150{ }^{\circ} \mathrm{C}$.

\section{References}

1. D.B. Spencer, R. Mehrabian, and M.C. Flemings, Rheological Behavior of Sn-15 Pct Pb in the Crystallization Range, Metall. Mater. Trans. B, 1972, 3, p 1925-1932

2. M.C. Fleming, Behavior of Metal Alloys in the Semisolid State, Metall. Mater. Trans. A, 1991, 22(5), p 957-981

3. Z. Fan, Semisolid Metal Processing, Int. Mater. Rev., 2002, 47, p 49-85

4. D.H. Kirkwood, Semisolid Metal Processing, Int. Mater. Rev., 1994, 39(5), p 173-189

5. W.J. Boettinger, S.R. Coriell, A.L. Greer, A. Karma, W. Kurz, M. Rappaz, and R. Trivedi, Solidification Microstructures: Recent Developments, Future Directions, Acta Mater, 2000, 48, p 43-70

6. H.V. Atkinson, Modelling the Semisolid Processing of Metallic Alloys, Prog. Mater Sci., 2005, 50, p 341-412

7. F. Taghavi and A. Ghassemi, Study on the Effects of the Length and Angle of Inclined Plate on the Thixotropic Microstructure of A356 Aluminium Alloy, Mater. Des., 2009, 30, p 1762-1767

8. Y. Birol, Cooling Slope Casting and Thixoforming of Hypereutectic A390 Alloy, J. Mater. Process. Technol., 2008, 207, p 200-203

9. B.K. Dhindaw, L. Kumar, N.C.A. Alkarkhi, and H. Fredricksson, Microstructure Development and Solute Redistribution in Aluminium Alloys Under Low and Moderate Shear Rates During Rheo Processing, Mater. Sci. Eng. A., 2005, 413-414, p 156-164

10. D. Liu, H.V. Atkinson, P. Kapranos, W. Jirattiticharoean, and H. Jones, Microstructural Evolution and Tensile Mechanical Properties of Thixoformed High Performance Aluminium Alloys, Mater. Sci. Eng. A, 2003, 361, p 213-224

11. T. Haga and P. Kapranos, Simple Rheocasting Processes, J. Mater. Process. Technol., 2002, 130-131, p 594-598

12. E.C. Legoretta, H.V. Atkinson, and H. Jones, Cooling Slope Casting to Obtain Thixotropic Feedstock II: Observations with A356 Alloy, J. Mater. Sci., 2008, 43, p 5456-5469

13. T. Haga and S. Suzuki, Casting of Aluminum Alloy Ingots for Thixoforming Using a Cooling Slope, J. Mater. Process. Technol., 2001, 118, p 169-172 
14. M. Nili-Ahmadabadi, F. Pahlevani, and P. Babaghorbani, Effect of Slope Plate Variable and Reheating on the Semi-Solid Structure of Ductile Cast Iron, Tsinghua Sci. Technol., 2008, 13(2), p 147151

15. E.C. Legoretta, H.V. Atkinson, and H. Jones, Cooling Slope Casting to Obtain Thixotropic Feedstock I: Observations with a Transparent Analogue, J. Mater. Sci., 2008, 43, p 5448-5455

16. H. Möller, G. Govender, and W.E. Stumpf, The T6 Heat Treatment of Semi-Solid Metal Processed Alloy A356, Open Mater. Sci. J., 2008, 2, p 6-10

17. M.H. Robert, E.J. Zoqui, F. Tanabe, and T. Motegi, Producing Thixotropic Semi-Solid A356 Alloy: Microstructure Formation x
Forming Behaviour, J. Achiev. Mater. Manuf. Eng., 2007, 20(1-2), p $19-26$

18. J. Southard, Flow in Pipes and Channels, Special Topics: An Introduction to Fluid Motions, Sediment Transport and Current Generated Sedimentary Structures, Massachusetts Institute of Technology: MIT Open Course Ware, USA. Accessed August 25, p 83-91, 2011

19. Heat Treating of Aluminum Alloys, ASM Handbook, vol. 4 (USA), ASM International, 2003, p 841-845

20. S. Kuntongkum, S. Wisutmethangoon, T. Plookphol, and J. Wannasin, Influence of Heat Treatment Processing Parameters on the Hardness and the Microstructure of Semi-Solid Aluminium Alloy A356, J. Met. Mater. Miner., 2008, 18(2), p 93-97 